
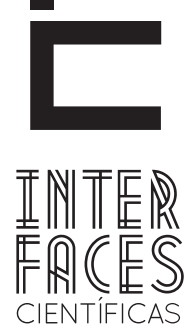

EDUCAÇÃo

ISSN IMPRESSO 2316-333X

ISSN ELETRÔNICO 2316-3828

Dossiê

\title{
AS MEMÓRIAS DE UM GRUPO DE PROFESSORES APOSENTADOS SOBRE SUAS FORMACÕES E AS PRÁTICAS PEDAGÓGICAS EM RONDONÓPOLIS-MT.
}

Wilson José Soares ${ }^{1}$

\section{RESUMO}

0 presente trabalho tem como objetivo discutir as trajetórias de formação e das práticas pedagógicas de um grupo de professores de Geografia aposentados. 0 método de estudo utilizado foi a pesquisa qualitativa com a metodologia de trabalho fundamentado na História Oral. A técnica de coleta das informações se deu com a gravação de depoimentos, e o recorte para o estudo se subdivide em três pontos bem definidos: o primeiro espacial, o município de Rondonópolis - Mato Grosso, Brasil;

o segundo, a rede pública de ensino e o terceiro, professores aposentados com idade acima dos sessenta anos. Os resultados apresentam a formação dos professores, em um ensino tradicional com a memorização dos conteúdos, prática fundamentada nas orientações curriculares da época.

\section{PALAVRAS-CHAVE}

Ensino. Geografia. Currículo. 


\section{ABSTRACT}

This paper aims to discuss the trajectories of training and pedagogical practices of a group of retired Geography teachers. The study method used was the qualitative research based on Oral History. The technique of data collection occurred with the recording of testimonies, and the study was divided into three well-defined points: the first related to the location, the municipality of Rondonópolis - Mato Grosso, Brazil, the second, the public school system and third, retired teachers over sixty years old. The results show the training of teachers, in a traditional school system with the memorization of contents, practice based on the curriculum guidelines of that time.

\section{KEYWORDS}

Teaching. Geography. Curriculum.

\section{RESUMEN}

Este trabajo tiene como objetivo discutir las trayectorias de formación y prácticas pedagógicas de un grupo de maestros jubilados de la Geografía. El método de estudio se utilizó la metodología de investigación cualitativa basada en la historia oral. La técnica de recolección de datos ocurrió con la grabación de las deposiciones y el recorte para el estudio se divide en tres puntos bien definidos: el primero de espacio, el municipio de Rondonópolis - Mato Grosso, Brasil, el segundo sistema de escuelas públicas y en tercer lugar, los profesores mayores de sesenta y jubilados. Los resultados muestran la formación de profesores en una escuela tradicional con la memorización de contenidos, práctica basada en los lineamientos curriculares de la época.

\section{PALABRAS CLAVE}

Educación. Geografía. Curriculum.

\section{CONHECER O ESPAÇO EM ESTUDO PARA ENTENDER AS MEMÓRIAS}

Rondonópolis é um dos 141 municípios do estado de Mato Grosso, localizado geograficamente na região sul do estado entre os paralelos $16^{\circ} 28^{\prime} 15^{\prime \prime}$ de latitude Sul e o Meridiano $54^{\circ} 38^{\prime} 08^{\prime \prime}$ de Longitude Oeste, sua área é de 4.258,20 km² e encontra - se a uma altitude média de 212 metros. A população, segundo o IBGE 2010 é de 195.472 habitantes, o clima é tropical úmido com uma temperatura média de 23 graus e o índice pluviométrico na média de $1.400 \mathrm{~mm}$ ao ano.

Devido ao fato do município estar em um ponto estratégico, no entroncamento de duas rodovias federais, as BRs 163 e 364, a migração para a região principalmente nos anos 1960, 1970 e 1980 foi muita intensa; parte dessa população ocupou inicialmente espaços rurais, no entanto, com as mudanças econômicas e sociais que vêm ocorrendo nestas últimas décadas, a população rural vem rompendo com o seu passado e tentando se ajustar a uma existência urbana, porém, a economia da cidade continua com sua base fundamentada no agronegócio, tanto na produção agrícola para exportação como a soja, milho e algodão quanto nas atividades industriais que estão direta ou indiretamente relacionada a esse modelo de produção.

Essa organização espacial tem produzido do ponto de vista econômico um forte desenvolvimento para a região, fato que é muito difundido pelos meios de comunicação local e até nacional, no entanto, junto a esse progresso somam-se também os graves proble- 
mas ambientais e sociais, esses, pouco discutido nos meios de comunicação, muitas vezes até ocultado intencionalmente.

Nesta perspectiva, cabe as profissionais da educação fomentar o debate e buscar soluções através das pesquisas e do diálogo com a sociedade. Sendo assim, entendemos que as aulas de geografia devem ser espaços para a realização desses entendimentos e, para tal, é necessá-

\section{PUXANDO O FIO DAS MEMÓRIAS}

As pesquisas sobre formação de professores apontam para uma revisão da compreensão das práticas pedagógicas numa perspectiva de construção e reconstrução dos conhecimentos. Compreender a educação nesta perspectiva requer do professor oportunizar aos estudantes práticas e reflexões que os proporcionem a interpretação da realidade, a construção da consciência política e a defesa dos bens coletivos. Para Oliveira (2002, p. 212), pensar a educação para a formação plena é ultrapassar a simples acumulação passiva dos conhecimentos, para produzi-la mediante a atividade exercida sobre os conteúdos, articulando-se uns com os outros e com a realidade vivenciada pelos educandos.

É com este entendimento de educação que foi puxado o fio condutor desta pesquisa desenvolvida no programa de Pós Graduação da UNESP Campus de Rio Claro São Paulo, no curso de Doutorado em Geografia. O objetivo do estudo foi compreender a trajetória de formação e ação pedagógica de um grupo de professores de Geografia aposentados que trabalharam na rede pública no município de Rondonópolis MT. Para essa compreensão, discutimos como a trajetória escolar e de formação continuada pode ter interferido no exercício profissional de cada um desses professores colaboradores. A faixa etária varia entre sessenta e dois e oitenta e cinco anos na época das entrevistas em 2010. rios que os professores dessa disciplina estejam preparados para provocar uma produção de conhecimentos desalienados e comprometidos com bem comum.

Neste sentido, esta pesquisa buscou através das memórias de professores de geografia aposentados compreender como essa disciplina foi organizada e trabalhada nas escolas públicas no município de Rondonópolis MT.
Para chegar ao resultado final do estudo foi utilizado como metodologia de trabalho a História Oral. A opção por esta metodologia se deu por ser, conforme Queiroz (1998), uma técnica que capta o que sucede na encruzilhada da vida individual com o social, o relato oral é a base de sustentação dos recursos de obtenção de dados e conservação do saber, uma vez que a palavra parece ter sido a primeira ou umas das mais antigas técnicas utilizadas para a obtenção de informações.

Os trabalhos com história oral, em contraposição aos dados quantitativos que reduz a realidade social na frieza dos números, vêm sendo considerado pelos cientistas sociais como uma técnica de excelência neste tipo de pesquisa, pois, possibilita a captação das experiências do narrador, suas tradições seus mitos, narrativas de ficção, suas crenças e as do seu grupo.

Conforme Portelli (2000, p. 69), quando se trabaIha com essa metodologia, “[...] parte de nosso desafio é o fato de que realmente encaramos a memória não apenas como preservação da informação, mas também como sinal de luta e como processo em andamento.” Segundo Delgado (2010, p. 38), “[...] a memória atualiza o tempo passado, tornando-o tempo vivo e pleno de significado no presente." 
Conforme Brito (1989), a memória do homem é determinada em seu contexto social, não como soma das memórias individuais, mas como resultante da vivência coletiva, é a releitura e reconstrução do passado com a inserção do indivíduo no grupo, alicerçada nos momentos presentes de sua vida. Para Halbwachs (2006), a memória social é partilhada e construída no grupo, ou seja, ela resulta de um trabalho coletivo, de uma vivência em comum, em um tempo e espaço determinado.

Nesta perspectiva, este estudo buscou compreender como estes professores foram formados e de que maneira conduziram suas ações ao passarem da condição de aluno para a de mediador da aprendizagem. Um mediador capaz de desenvolver nos seus alunos competências e habilidades de leitura e interpretação das configurações espaciais em todas as escalas. As análises deste trabalho estão apoiadas na pesquisa qualitativa, mais precisamente, com o registro de depoimentos da trajetória escolar e profissional desse grupo de professores.

\section{INTERPRETANDO AS MEMÓRIAS}

As memórias registradas nos possibilitou organizá-las em dois grandes grupos bem definidos: o primeiro se subdivide em duas partes, a composta pelos professores que tiveram uma formação fragmentada e/ou a distancia em cursos cujo objetivo foi à certificação sem a devida preocupação com a qualidade do ensino e; os que durante sua carreira profissional desenvolveram paralelamente outras atividades remuneradas. 0 segundo grupo é composto por aqueles que tiveram uma formação mais consistente e com dedicação exclusiva ao magistério.

0 elo entre esses dois grupos de professores está no início das atividades pedagógicas, conforme Leite
Para Goodson (2007, p. 72), as narrativas de professores são muito significativas, elas possibilitam fazer a interação entre as histórias de vida com a história da sociedade, da escola, da disciplina e da profissão, portanto, compreendo que as narrativas não são reinterpretações do ocorrido no passado, uma vez que, em conformidade com Bosi (1994, p. 20) "lembrar não é reviver". É uma reflexão, é compreender o agora a partir de outrora "é sentimento, reaparição do feito e do ido, não sua mera repetição."

Os registros foram analisados dentro do contexto do período que os depoentes foram formados e desenvolveram suas atividades como docentes, os relatos registrados pelas memórias estão conforme as orientações curriculares e os entendimentos sobre educação da época, mesmo assim foi decidido preservar a identidade dos professores. Por isso, os nomes citados no texto são fictícios, foi mantido apenas a letra inicial de cada nome, tanto das pessoas quanto das escolas que fazem referências. A única exceção é o da UFMT (Universidade Federal de Mato Grosso) Campus Rondonópolis.

(1940), devido o estado de Mato Grosso estar geograficamente distante dos grandes centros e com uma densidade demográfica muito baixa a dificuldade de encontrar professor habilitado foi uma das maiores dificuldades dos gestores públicos, por isso, todos os depoentes ainda em formação, em alguns casos no ensino fundamental e menores de idade já assumiram o exercício do magistério.

As narrativas das professoras Luzia e Inês evidenciam essa problemática ao relatarem que na adolescência, quando cursavam o ginásio ( $5^{\mathrm{a}}$ a $8^{\mathrm{a}}$ série), foram recrutadas para dar aulas nas escolas isoladas da periferia da cidade de Rondonópolis e, ou na zona 
rural. A professora Inês afirma que: "quando eu fiz admissão na escola São Francisco de Assis, eu fui uma das melhores alunas, e o prefeito da época, Damião Matos chamou meu pai e disse que queria que eu fosse dar aulas numa região aqui perto, comecei a dar aulas muito cedo".

No caso da professora Luzia, a necessidade de trabalhar levou-a para a zona rural. Sua memória registra que: "fiz o exame de admissão com bom aproveitamento, mas parei, parei e voltei para a roça, fui lecionar lá, eu já sabia um pouquinho e a necessidade me fez voltar a trabalhar lá, fiquei até me casar". Neste caso, dois fatores foram determinantes: o primeiro as condições econômicas da família da professora que não era diferente da maioria das demais e; segundo a falta de professores habilitados para atender a demanda.

Essa carência de formação e as orientações curriculares da época culminaram em uma prática pedagógica pautada na "educação bancária" discutida por Freire (2005), em sua obra "pedagogia do oprimido". Os registros da produção e reprodução dessa prática estão evidenciados na memória do professor Antônio, ele diz que sua metodologia de ensino teve como fundamentação uma de suas professoras formadora na época que estudou na Escola São Francisco de Assis, ele narra que:

[...] eu até peguei com ela um ponto de referência como dar aulas, por que ela chegava no horário, "boa noite", passava a disciplina no quadro, copiava tudo que ela passou, fazia a chamada, e terminava de explicar tudo àquilo que ela passou e quando terminava de explicar batia o sinal, vou te dizer, era cronometrista de primeira nas aulas dela! Ela era excelente![...]

0 professor Antônio relata também que nesta época a irmã diretora da escola batia nos alunos com varas e ele defende que essa é uma prática necessária nas escolas para que os alunos obedeçam aos professores. As professoras Inês e Marta também acreditam que o castigo ajudam as crianças a terem mais compromisso com os estudos e a obedecer às ordens dos professores.
O professor Antônio e a professora Inês entendem que as orientações dos estudos da psicologia na educação e as teorias progressistas tem dado muita liberdade aos alunos e as tornados muito "indisciplinados", eles defendem o castigo como forma de forçar os alunos aprenderem os conteúdos.

As orientações curriculares progressistas explicam que a metodologia de ensino defendida por esses professores dificulta a compreensão dos conteúdos estudados e a sua relação entre as aulas e as práticas cotidianas, o ensino não está contextualizado com a realidade dos alunos. Nóvoa (2011, p. 23), explica que "[...] os conteúdos não valem por si só isolados do contexto de sentido de um sujeito que os aprendem". Nessa mesma frente de orientação pedagógica Freire (2011, p. 227), diz que o professor formado no modelo conservador tem dificuldades de superar a dicotomia e integrar a palavra e o mundo.

A aprendizagem pautada no ritmo da memorização, chamada pro Freire (2005) de "educação bancária”, é medida através da reprodução fiel na hora da prova de tudo aquilo que os professores "detentores do conhecimento" thes repassaram durante as aulas.

A contextualização dos conteúdos está mais clara nos depoimentos dos professores Bento, Elza, Luzia e Marta que tiveram uma formação mais sólida e conseguiram avançar um pouco mais no sentido de dar criticidade as observações. A professora Marta relata que orientava os alunos a observarem a trajetória de casa até a escola, como a vegetação do cerrado e as transformações que ocorriam no espaço vivido. A professora Luzia diz também, que fazia pesquisa com seus alunos na comunidade, entrevistavam os moradores e depois trabalhavam com os dados em sala de aula, já os professores Bento e Elza relataram que utilizavam os noticiários como material pedagógico para interpretar a organização espacial e social.

Bento e Elza também diz que analisavam os livros didáticos de forma crítica, pois traziam conteúdos que 
não atendiam as necessidades dos alunos, o professor Bento em sua memória registra que no:

[...] caso de Geografia, vinha com exemplos dos Estados Unidos, essas histórias, mas nós estamos no Brasil, estamos no Mato Grosso, Rondonópolis. Então eu procurava sempre encaixar, eu falava pra eles, primeiro tem que conhecer sua casa, depois se sobrar tempo vou estudar fora, minha filosofia sempre foi essa.

Essa narrativa demonstra uma reflexão mais elaborada sobre o ensino de Geografia, no entanto, com o desenvolvimento do capitalismo, não é possível discutir os problemas locais sem fazer a conexão com os problemas globais, as fronteiras foram alargadas; local e global estão, de certa forma, juntos, problemas aparentemente localizados têm origem em outros continentes.

Mesmo com as limitações para uma leitura mais critica da complexidade da organização espacial o professor não deixa dúvidas de quanto se preocupava com o ensino da Geografia de forma contextualiza e tentava romper com a cultura do ensino memorístico.

Outro exemplo de preocupação com a abstração dos conteúdos do livro didático é o da professora Luzia, em sua memória ela relata um episódio de quando esteve em uma de suas viagens de férias. A professora esclarece que:

[...] lembro que quando eu falando para eles daquele meteoro que caiu em Bedengó na Bahia, falei, falei, falei, parece que eu estava lá vendo o lugar onde ele caiu, a cratera que ele abriu e as crianças ficavam empolgadas querendo também vivenciar aquele assunto. A maior surpresa que tive foi quando estava percorrendo o Museu Nacional no Rio de Janeiro, lendo as plaquinhas vi aquela pedra, eu li na plaquinha, ahhh! 0 meteoro que caiu em Bedengó na Bahia, eu falei: não é possível! Peguei nele, apalpei, mais não é possível! Eu tinha a impressão de que era mais ou menos do tamanho de um terreno como esse aqui, era simplesmente uma pedra que dá para ser abraçada, eu digo: meu Deus! Se eu tinha aquela ideia tão abstrata, e as crianças que eu falava para eles? Que ideia eles têm? Não é mesmo? Quer dizer, tem coisa que a gente explica, explica e não diz nada.
Quando a professora fala que pensava ser o meteoro do tamanho "de um terreno como esse aqui," ela se refere ao espaço que está construído sua residência, uma área de aproximadamente $12 \times 30$ metros, como são a maioria das parcelas dos lotes urbanos em Rondonópolis.

Sua percepção de professora observadora the possibilita a compreensão de que quando as atividades são movimentadas, a aprendizagem torna-se mais significativa e desperta o interesse dos alunos, que não se cansam. Quando uma atividade é parada, de leitura e cópia, em pouco tempo os alunos estão desconcentrados e perdem o interesse pelo saber.

Quanto ao ensino de cartografia, as memórias são muito semelhantes, as referências são de aulas com mapas para que os alunos localizassem os lugares, os nomes dos países e suas capitais, uma função contemplativa e não de leitura e interpretação do espaço. Os professores João e Inês relatam que tinham dificuldades em trabalharem a cartografia até com essas atividades de observações e localizações dos lugares nos mapas, em suas narrativas afirmam que quando chegavam nesse conteúdo chamavam outro colega com maior habilidade para explicar para os alunos.

Os discursos dos professores colaboradores neste trabalho evidenciam a importância do contato com os professores que fizeram parte de suas formações acadêmicas. As narrativas daqueles que se mostravam estar mais comprometidos com a construção do conhecimento de seus alunos narram que tiveram influências marcantes de seus formadores.

A depoente Marta, por exemplo, afirma que sua participação nas aulas da professora Carmem na UFMT, Campus Rondonópolis, no curso de Estudos Sociais, alterou completamente seus conhecimentos geográficos. Essas aulas thes proporcionaram repensar sua prática e ressignificar suas aulas com novas metodologias. Ela recorda do tempo em que estudava Geografia na educação básica e afirma que não en- 
tendia nada dos conteúdos ensinados, pois conforme sua interpretação, eles não faziam inferências ao seu cotidiano e narra que: "(...) a professora estava falando de uma coisa que eu nunca tinha visto. Decorava, mas não entendia."

Esse mesmo entendimento pode ser verificado na memória da professora Luzia, que também estudou com a professora Carmem. Sua memória apresenta essa professora como muito prática, que ensinava os conteúdos da Geografia relacionados com o cotidiano dos estudantes, incentivando o grupo a refletir acerca das ações antrópicas no espaço natural.

Por meio dos relatos destas docentes, é possível inferir que a atuação da professora Carmem foi fundamental para a formação dos professores de Geografia que estudaram na UFMT, Campus Rondonópolis. Todos os depoentes que estudaram nesta universidade têm em sua memória esse nome como referência. Em contrapartida, os professores que tiveram uma formação em cursos superiores na modalidade à distância foram os mesmos que apresentaram uma formação mais precária, no que se refere à disponibilidade e qualidade de informações consistentes. As próprias memórias desse período foram, em geral, apresentadas de maneira vaga, fragmentadas, em alguns casos, esses professores não vivenciaram estratégias e metodologias de ensino diferenciadas, os discursos são pouco consistentes, em geral, caíam em contradição e, na sequência da narrativa, deixavam dúvidas ao se referirem as trajetórias vividas.

Em suas narrativas, esclarecem que as preocupações eram voltadas apenas para os conteúdos escolares a serem trabalhados a partir da organização curricular e dos valores religiosos, segundo suas crenças. Os relatos das aulas desses professores estão vinculados a uma Geografia supostamente neutra, sem um posicionamento ideológico explícito. As narrativas de suas aulas estavam voltadas para a aprendizagem dos conteúdos.
Sobre tal comportamento, Silva (2011, p. 23), analisando a identidade do currículo afirma que, no modelo tradicional, a escola deveria funcionar como "uma empresa comercial ou industrial", com o estabelecimento de metas e resultados mensuráveis. Por isso, a preocupação dos professores voltava-se aos conteúdos e não às experiências que cada aluno tinha ao chegar à escola.

Nas narrativas dos dois grupos pode se perceber a ausência de memórias que denotem reflexões sobre as políticas que norteavam o ensino e a organização econômica, sócio-espacial do período em que estiveram em formação e/ou exercendo a docência. Seus depoimentos misturam lembranças do tempo em que foram estudantes e professores com o que observam na atualidade, por isso, muitos trechos das narrativas são contraditórios. Contudo, as memórias estão sempre relacionadas com a aprendizagem dos conteúdos a serem ensinados, pois, foi nesta organização de ensino que foram formados e foram com essas mesmas orientações curriculares que trabalharam.

Estas memórias contraditórias podem ser entendidas como uma tentativa de reconstruir o passado a partir do entendimento atual, Portelli (2000, p. 69), orienta que nesse tipo de pesquisa o desafio é o fato de que realmente se encara a memória não apenas como preservação de informações, mas como sinal de luta e processo em andamento. Assim, necessário se fez compreender o momento histórico em que esses professores foram formados e exerceu a profissão, quais os direcionamentos que o poder público dava para a educação, quais objetivos estavam estabelecidos para o ensino das ciências sociais e para os conhecimentos geográficos, como também quais os entendimentos que se tem nos dias atuais acerca da educação e da Geografia escolar. Essas problemáticas não podem ser esquecidas quando se analisa as memórias desses professores, caso contrário, as interpretações podem incorrer em informações falsas quanto ao comprometimento com o ensino do grupo estudado. 
As memórias do grupo de depoentes registram que as referências metodológicas utilizadas por seus professores, foram às referências para suas atividades no início da carreira docente. Aulas pautadas em conteúdos dos livros didáticos, em que os professores ensinavam fundamentados nas informações das "lições" do livro ou em textos que discutiam espaços muito distantes da realidade dos alunos.

0 professor Antônio tem ainda muito vivo em sua memória um texto de quando estava sendo alfabetizado e que discutia a rotina de um vaqueiro chamado seu Fulgêncio, que vivia na Ilha de Marajó, Pará. Em sua narrativa, afirma ter sido aquela paisagem responsável pelo seu interesse em cursar a faculdade de Geografia. Este mesmo texto foi recordado pela professora Luzia, ao falar dos livros didáticos com os quais estudava e utilizou para ministrar suas aulas.

Os textos ilustrativos contidos nos livros didáticos do período foram responsáveis pela divulgação das belezas naturais brasileiras, sem discutir os problemas reais que afligiam a população. Eles buscavam a construção de uma ideologia naciona- lista e estavam inseridos em um contexto histórico e espacial específico.

Os depoimentos aqui registrados, evidenciam a importância da formação inicial e continuada dos professores, uma vez que as narrativas são unânimes em reconhecer essa formação como fundamental para o exercício do magistério. No entanto, para que a formação possa se efetivar é necessário provocar na prática de sala de aula situações que desencadeiem processos e desafiem o aprimoramento intelectual dos alunos. Os professores precisam empregar métodos ativos que engendram ações didáticas em bases sólidas, tornando o ensino de Geografia capaz de promover o desenvolvimento intelectual, com vistas à formação de uma cidadania responsável, consciente e atuante.

Nessa complexa organização espacial, os professores de Geografia precisam saber interpretar o espaço geográfico e os períodos históricos para chegar à síntese, é preciso proporcionar aos alunos condições necessárias ao entendimento da Geografia escolar como conhecimento que estuda o espaço construído pelo homem ao longo de sua história.

\section{CONSIDERAÇÕES FINAIS}

Ao analisar as memórias desses professores, pode se considerar que suas atividades formativas e pedagógicas estão marcadas pela organização curricular da época, como não podia ser diferente, no entanto, a formação do professor como é entendida hoje, na perspectiva progressista é de que o ensino precisa contribuir para o entendimento de que o eixo da práxis passa a ser o sujeito e não os conteúdos. Porém, isso não significa que os conteúdos não tenham significados, eles são os instrumentos culturais e precisam ser estudados, sem conteúdo não é possível haver produção de conhecimento.
Este entendimento pode levar a uma mobilização em favor da desconstrução da escola seletiva e excludente, para a busca incessante pela escola inclusiva, a escola como um espaço que a discussão passe da afirmação de que "se o aluno não aprendeu, reprova", para o seguinte questionamento: "o que precisamos fazer para que ele aprenda?"

Entender essas exigências significa entender que a formação do professor não termina na graduação, ela é uma atividade cotidiana, é um compromisso profissional na perspectiva da construção de novos sabe- 
res, troca de experiências e atualização. Neste contexto, entendo que a história de vida desses professores contribuiu sobremaneira para a compreensão da história do ensino de Geografia em Rondonópolis - MT e anseio que tal contribuição possa ser considerada de maneira significativa para que se repense as propostas e práticas de ensino em relação a esta disciplina escolar. Reflexões estas que poderão apontar novos rumos a serem trilhados na busca das mudanças necessárias para uma educação mais humanizadora.

É nesta esperança de poder contribuir para a melhoria do ensino de Geografia que encerro este exercício de reflexão, não como um ponto final, mas com a certeza da possibilidade de permanente continuidade.

\section{REFERÊNCIAS}

BOSI, Ecléa. Memória e sociedade: lembrança dos veIhos, 15. Ed. São Paulo: Companhia das Letras, 1994.

BRITO, Marilza Elizardo. Memória e cultura. In: cadernos da memória da eletricidade. Centro de memória da eletricidade no Brasil, Rio de Janeiro: 1998. P, 3-20.

DELGADO, Lucília de Almeida Neves. História oral: memória, tempo, identidade. 2. ed. Belo Horizonte: Autêntica, 2010.

FREIRE, Paulo; SHOR Ira. Medo e ousadia: o cotidiano do professor. 13. ed. São Paulo: Paz e Terra, 2011.

FREIRE, Paulo. Pedagogia do Oprimido. Rio de janeiro: Paz e Terra, 41. ed. 2005.

FONTOURA, Maria Madalena. Fico ou vou - me embora? In: NÓVOA, Antônio. (Org.). Vida de professores. 2. ed. Porto: Porto. 2007. p. 171-197. (Coleção ciência da educação).

GOODSON, Ivor F. Dar voz ao professor: as histórias de vida dos professores e o seu desenvolvimento profissional. IN: Nóvoa Antônio (Org.). Vida de professores. Coleção ciência da educação, 2. Ed. Porto Portugal: Porto. 2007. Cap. 3, p. 63 - 78.
GUIMARÂES, Dulci Maria Pamplona. Memória e história oral. In: Revista DIALOGUS, n. I. Ribeirão Preto: 2005. p. 11-18. V. 1.

HALBWACHS, Maurice. A memória coletiva. Tradução SIDOU, Beatriz. São Paulo: Centauro. 2006.

LEITE, Gervásio. Um século de Instrução Pública. Goiânia: Rio Bonito, 1970.

NÓVOA, António. Os Professores e a as histórias de suas vidas. In: Nóvoa (Org.). Vida de professores. 2. ed. Porto: Porto. 2007. Cap. 1, p. 11 - 30. (Coleção ciência da educação).

PORTELLI, Alessandro. Memória e diálogo: desafios da história oral para a ideologia do Século XXI. In: FERREIRA. Marieta de Moraes. (Org.). Desafios para o século XXI. Rio de Janeiro: Fiocruz casa de Osvaldo Cruz - CPDOC Fundação Getúlio Vargas, 2000. Cap. 4, p. 67-71.

OLIVEIRA, Ariovaldo Umbelino de. PONTUSCHKA, Nidia Nacib. Geografia em Perspectiva. SP. Contexto, 2002. P, 187 a 194.

QUEIROZ, Maria Isaura Pereira de. Experimento com história de vida (Brasil - Itália), Revistas dos Tribunais Ltda. São Paulo 1988. 
SILVA, Tomaz Tadeu da. Documentos de identidades:

uma introdução as teorias do currículo. 3. ed. Belo

Horizonte: Autêntica, 2011.

1 Professor do curso de Geografia no IFMT (Instituto Federal de Educação Ciências e Tecnologia de Mato Grosso), campus Rondonópolis. Email: Wilson.soares@roo.ifmt.edu.br 